\title{
BMJ Open Effectiveness of solar disinfection water treatment method for reducing childhood diarrhoea: a systematic review and meta-analysis
}

\author{
Negasa Eshete Soboksa (D) , ${ }^{1}$ Sirak Robele Gari, ${ }_{3}$ Abebe Beyene Hailu, ${ }^{2}$ \\ Dereje Oljira Donacho, ${ }^{2}$ Bezatu Mengistie Alemu ${ }^{3}$
}

To cite: Soboksa NE, Gari SR, Hailu $A B$, et al. Effectiveness of solar disinfection water treatment method for reducing childhood diarrhoea: a systematic review and meta-analysis. BMJ Open 2020;10:e038255. doi:10.1136/ bmjopen-2020-038255

- Prepublication history and additional material for this paper is available online. To view these files, please visit the journal online (http://dx.doi.org/10. 1136/bmjopen-2020-038255).

Received 05 March 2020 Revised 07 November 2020 Accepted 19 November 2020

Dheck for updates

(C) Author(s) (or their employer(s)) 2020. Re-use permitted under CC BY-NC. No commercial re-use. See rights and permissions. Published by BMJ.

${ }^{1}$ Ethiopian Institute of Water Resources, Addis Ababa University, Addis Ababa, Ethiopia ${ }^{2}$ College of Public Health and Medical Sciences, Jimma University, Jimma, Ethiopia

${ }^{3}$ College of Health and Medical Sciences, Haramaya University, Harar, Ethiopia

Correspondence to Mr Negasa Eshete Soboksa; yeroosaa@gmail.com

\section{ABSTRACT}

Objective This study aimed to pool out the available evidence on the effectiveness of the solar disinfection water treatment method for reducing childhood diarrhoea. Design Systematic review and meta-analysis.

Setting Global.

Methods Searches were conducted in Medline/PubMed, Scopus, Google Scholar, Cochrane Library databases and references to other studies. The review included all children living anywhere in the world regardless of sex, ethnicity and socioeconomic status published in English until December 2019. Studies that compared the diarrhoea incidence between the intervention group who were exposed to solar disinfection water treatment and the control group who were not exposed to such water treatment were included. The outcome of interest was the change in observed diarrhoea incidence and the risk from baseline to postintervention. Two independent reviewers critically appraised the selected studies. Effect sizes were expressed as risk ratios, and their $95 \%$ Cls were calculated for analysis.

Results We identified 10 eligible studies conducted in Africa, Latin America and Asia that included 5795 children aged from 1 to 15 years. In all identified studies, solar disinfection reduced the risk of diarrhoea in children, and the effect was statistically significant in eight of the studies. The estimated pooled risk ratio of childhood diarrhoea among participants that used the solar disinfection water treatment method was $0.62(95 \% \mathrm{Cl}$ 0.53 to 0.72 ). The overall pooled results indicated that the intervention of solar disinfection water treatment had reduced the risk of childhood diarrhoea by $38 \%$.

Conclusions The intervention of solar disinfection water treatment significantly reduced the risk of childhood diarrhoea. However, the risk of bias and marked heterogeneity of the included studies precluded definitive conclusions. Further high-quality studies are needed to determine whether solar disinfection water treatment is an important method to reduce childhood diarrhoea. PROSPERO registration number CRD42020159243

\section{INTRODUCTION}

Diarrhoea is the second leading cause of death in children under 5 years of age, and an estimated 2.5 billion cases of diarrhoea
Strengths and limitations of this study

- Study selection, data extraction and quality assessment were independently performed by two review authors.

- This review was the first meta-analysis done on solar disinfection, water treatment methods and the risk of childhood diarrhoea.

- The limitations of this study were, we tried to include only published articles, excluding unpublished articles/resources and restrictions to studies written in English.

occur and are responsible for killing around 760000 children every year. More than half of these cases are in Africa and South Asia, where the attacks of the diseases are more likely to result in death or other severe outcomes. ${ }^{1}$ This diarrhoea-related death in low-income andmiddle-income countries is mostly attributable to inadequate water, sanitation and hygiene. ${ }^{2}$ The deaths of 279000 children aged under 5 each year could be avoided if the risk factors were addressed. ${ }^{3}$ Previous systematic review findings suggest that point-of-use water treatment is one of the most effective strategies to reduce diarrhoea among children under 5 years of age. ${ }^{4-7}$

The importance of household water treatment and safe storage (HWTS) in reducing diarrhoeal disease has been increasingly recognised. ${ }^{8} 9$ Solar disinfection (SODIS) method is recognised as one viable HWTS option. ${ }^{10}$ It is the simplest, cheapest technology, and effective water treatment method that applies to emergencies, especially when no chemical disinfectants are available. ${ }^{11}$ The method relies on disposable transparent plastic or glass containers which are then exposed to the sun and its germicidal effect is based on the combined effect of thermal heating of solar light and UV radiation. ${ }^{12-14}$ 
Since SODIS is simple to use and inexpensive, the method has spread throughout the low-income andmiddleincome world and is in daily use in $>50$ countries in Asia, Latin America and Africa. More than 5 million people disinfect their drinking water with the SODIS technique as the report of a systematic review. ${ }^{14}$

SODIS has been repeatedly shown to be effective for eliminating microbial pathogens and reducing diarrhoea morbidity, but its effectiveness is limited to waters of low turbidity. ${ }^{12}{ }^{15}$ Earlier cluster-randomised controlled trial studies showed that the SODIS of drinking water reduced diarrhoea among under-5 children. ${ }^{16-18}$ A matched casecontrol study done in India also concludes that SODIS of water can significantly decrease diarrhoea morbidity in children. ${ }^{19}$ Other study findings reported from Kenya showed that children drinking solar disinfected water had a significantly lower risk of severe diarrhoeal disease over 87052 weekly follow-up visits; the 2 weeks prevalence of diarrhoea in the intervention group was $48.8 \%$ compared with $58.1 \%$ in controls, corresponding to an attributable fraction of $16.0 \%{ }^{17}$ Studies reported from Bolivia and Peru showed that there was no statistically significant difference in the number of diarrhoea episodes between the SODIS and control arms of the study. ${ }^{18} 20$

Other studies showed that SODIS was essential among household water treatment and safe storage for the reduction of diarrhoea. However, the reported findings revealed heterogeneous outcomes. More importantly, a systematic review and meta-analysis have not been done to pool the evidence of the effectiveness of the SODIS water treatment method for reducing diarrhoea. Therefore, the objective of this review was to pool out the available evidence on the effectiveness of the SODIS water treatment method for reducing diarrhoea. The research question of this review was 'Does solar disinfection water treatment method improve the microbial quality of drinking water and reduce childhood diarrhoea?'

\section{METHODS}

\section{Protocol development}

This systematic review and meta-analysis has been written following the Preferred Reporting Items for Systematic Review and Meta-analysis (PRISMA) statement guidelines $^{21}$ (see online supplemental file 1). Before undertaking the review, we registered the protocol in PROSPERO (CRD42020159243) and the detail of this systematic review and meta-analysis protocol has been published elsewhere. ${ }^{22}$

\section{Data sources and search strategy}

An electronic database search was carried out to identify appropriate peer-reviewed articles that met the inclusion criteria. We searched PubMed/Medline, Scopus, Google Scholar, Cochrane Library databases and references to other studies. We used a combination of Medical Subject Heading terms and keywords terms: (solar energy OR sunlight) AND (water disinfection OR water purification
OR water treatment) AND (diarrhea OR diarrhoea OR dysentery) AND (children OR child OR childhood). The search of the literature was conducted in December 2019. The search strategy was limited to studies published in English language literature (see online supplemental file 2: full search strategy for PubMed/Medline and Cochrane library databases). The results of the search and the full process for selecting included the studies were reported and presented in a PRISMA flow diagram. ${ }^{23}$

\section{Criteria for considering studies for this review}

Studies that met the following criteria were included in this review.

\section{Types of studies}

We included only randomised controlled trials studies that assessed the effectiveness of the SODIS water treatment methods for reducing diarrhoea and published in English until December 2019.

\section{Participants}

The review included all children living anywhere in the world regardless of sex, ethnicity and socioeconomic status.

\section{Interventions and comparator}

This review considered studies that evaluated the effectiveness of SODIS as a water treatment method for the reduction of diarrhoea. Studies that compared the diarrhoea occurrence among the intervention group children who were exposed to SODIS water treatment and control group children who were not exposed to such water treatment were considered.

\section{Types of outcome measures}

This review considered studies that included the incidence rates of diarrhoea (non-bloody, with dehydration, dysentery), defined as the number of diarrhoea (three or more loose or watery stools during 24 hours or any loose stool that contained blood or mucus) episodes per child per year obtained from a daily assessment of the individual diarrhoea occurrence. The primary outcome of this study was the change observed in diarrhoea incidence after SODIS was applied for the treatment of drinking water.

\section{Data collection and analysis}

\section{Data management and selection of studies}

Mendeley Desktop reference management software V.1.19.5 (Mendeley, Elsevier, The Netherlands) was used to combine search results and to remove duplicate articles. Two independent reviewers (NES and DOD) conducted the screening of included studies. The articles found by searches in databases were evaluated for inclusion at three levels, that is, by title, then by abstract and finally by full text. The full text of selected studies was retrieved and assessed in detail against the inclusion criteria. Discrepancies were discussed between reviewers and agreement was reached about whether to include the study or not. For the screening of articles at the full-text level, rejection of an 
article was decided by the review team on the suggestion of the first reader. The details regarding the final decision of inclusion of articles were clarified and archived in a database. In case of uncertainty in the decision, whether to include the study or not, the reviewer included this article for the next level of screening. The documents without abstracts were screened at the full-text level. A list of articles excluded at the full-text level was provided in the systematic review, accompanied by reasons for exclusion.

\section{Data extraction}

The data were extracted from studies included in the review using the prepared data extraction tool form by two independent review authors (NES and DOD). For each study, the authors' name, place and year of publication, data on sample size and characteristics, characteristics of interventions performed, results of included studies, and follow-up of the study were extracted. The data extraction form was pretested with three randomised controlled trials similar to those eligible in this review. Any disagreements that arise between the reviewers were resolved through discussion or with a third reviewer (BMA).

\section{Risk of bias of included studies}

The methodological quality of the studies that met the selection criteria were evaluated independently by two authors (NES and DOD) using the revised Cochrane risk-of-bias tool for randomised trials outlined in the Cochrane Handbook for Systematic Reviews of Interventions. ${ }^{24}$ This method classifies bias in randomised studies as 'low', 'high' or 'unclear' based on the presence or absence of six processes (random sequence generation, allocation concealment, blinding participants or investigators, incomplete outcome data, selective reporting and other biases). These were identified based on both empirical evidence and theoretical considerations. The rating for each bias criterion of the two authors was compared. Disagreements between the two authors on individual bias criteria were identified and discussed in an attempt to reach a consensus. Any disagreements that arose between the reviewers were resolved through discussion or in consultation with a third reviewer.

\section{Measures of treatment effect}

It is expected that SODIS water treatment intervention reduces the risk of diarrhoea, and we used the risk ratio (RR). RR was estimated by using the following data: the number of participants who experienced diarrhoea and the total number of participants in each group. $R R<1$ indicated that SODIS water treatment results in a greater chance of decreasing diarrhoea.

\section{Dealing with missing data}

We contacted the authors for missing data and clarity of primary studies if required; such inclusions were reported in the review.

\section{Data synthesis and assessment of heterogeneity}

We conducted a narrative synthesis first to describe the study details, participant and intervention characteristics and outcomes of the included studies. Then meta-analysis was conducted using Comprehensive Meta-Analysis V.3.3 (Biostat, USA). We calculated 95\% CIs and two-sided $\mathrm{p}$ values for the outcome. Heterogeneity was assessed using the Cochrane $\chi^{2}$ test (Q-test) statistics and inverse variance index $\left(\mathrm{I}^{2}\right)$ statistics. An $\mathrm{I}^{2}$ value, a measure that ranges from $0 \%$ to $100 \%$, was classified as follows: no relevant heterogeneity $(0 \%-25 \%)$, moderate heterogeneity $(25 \%-50 \%)$ and significant heterogeneity $(>50 \%) .{ }^{25} \mathrm{~A}$ high degree of heterogeneity was observed for the outcome, and thus, we used a random-effects model to estimate the pooled RR. Forest plots were generated to present the pooled estimates. In the forest plot, the size of each circle revealed the weight of the study, while each crossed line refers to a 95\% CI. Moreover, the diamond represents the overall effect, whereas the width of the diamond shows the CIs for the overall effect estimated. We performed subgroup analyses to investigate the possible sources of heterogeneity using follow-up periods of the studies, the age of the included participants and the region of study settings/ continent. The presence of publication bias was examined using a funnel plot and Egger's test. A sensitivity analysis was repeated 10 times after excluding one study using a random-effects model to observe the impact of the individual study on the overall RR.

\section{Patient and public involvement}

No patient involved.

\section{RESULTS}

\section{Study selection}

The search strategy resulted in 1678 records from electronic databases and hand searches. Out of these records, we identified 1527 records after duplicates removed. After reviewing the titles/abstracts, 1482 records were excluded and 45 full-text articles assessed for eligibility. Of the 45 articles selected for potential eligibility, 32 were excluded as they did not relate to our study question. The other three articles were excluded due to their study design and study participants. ${ }^{26-28} \mathrm{~A}$ list of articles excluded at the full-text level and reasons for exclusion are illustrated in online supplemental file 3 . The remaining 10 studies were included in the present systematic review and metaanalysis $^{16-2029-33}$ (figure 1).

\section{Study characteristics}

Table 1 summarises the characteristics of the studies included in this meta-analysis. All the included studies were intervention-based studies that were conducted from 1996 to 2018 in seven low-income andmiddleincome countries. Among the 10 studies, 6 studies were conducted in Africa, ${ }^{16}$ 17 29-32 2 studies were conducted in Latin America ${ }^{18} 20$ and the remaining 2 studies 

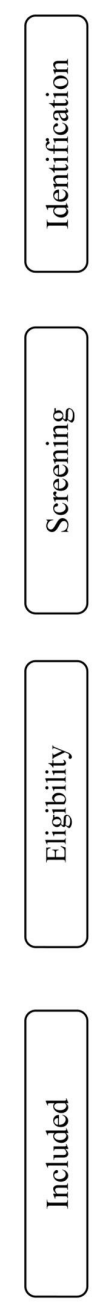

Records identified through searching of Medline/PubMed, Scopus, Google Scholar, Cochrane Library databases, and references to other studies (1678)

Figure 1 Flow diagram of included relevance studies identified by the systematic search strategy. RCT, randomised controlled trial; SODIS, solar disinfection.

were conducted in Asia. ${ }^{19} 33$ Regarding the included studies setting, seven studies were conducted in a rural area. $^{16-18} 2030-33$ The total study participants were 5795 children aged 1-15 years live in households using SODIS and no intervention (table 1 ).

\section{Risk of bias in individual studies}

Risk of bias assessment is presented in figure 2. Based on the results of the study's risk of bias assessment, we have judged seven studies as having a low risk, two studies were judged as having some concerns and the remaining one study was judged as having a higher risk of bias (figure 2).

\section{Childhood diarrhoea}

SODIS water treatment method reduced diarrhoea in children in all studies identified. After the implementation of the SODIS water treatment method, the risk of childhood diarrhoea was significantly reduced in eight studies with a RR range of $0.16-0.70$ at $95 \%$ CI. In two studies, childhood diarrhoea was reduced but the reduction was not statistically significant. In this meta-analysis, we found a significant heterogeneity across the studies $\left(\mathrm{I}^{2}=74.37 \%\right.$, $\mathrm{p}=0.000$ ). As presented in figure 3 , the overall pooled $R R$ of childhood diarrhoea reported by the 10 studies using the random-effects model was 0.62 (95\% CI 0.53 to 0.72 ). These imply that the effect of diarrhoea was significantly $(p<0.000)$ reduced by $38 \%$ using the SODIS water treatment method (figure 3).

\section{Subgroup analysis}

The results from subgroup analysis are summarised in figures 4-6. In the figures, the presence of heterogeneity was assessed by subgroup analysis. In figure 4 , the level of heterogeneity was decreased for 3 months follow-up and there is no evidence of heterogeneity for 6 months follow-up. We found a RR of diarrhoea reduction by $39 \%$ for 3 months, $35 \%$ for 6 months and $41 \%$ for 12 months follow-up. The pooled RRs for each group were 0.61 (95\% CI 0.43 to 0.86 ) for 3 months follow-up, 0.65 (95\% CI 0.48 to 0.87 ) for 6 months follow-up and 0.59 (95\% CI 0.43 to 0.80 ) for 12 months follow-up (figure 4 ). The pooled RRs for the subgroup analysis based on the age of study participants were 0.59 (95\% CI 0.46 to 0.76 ) for age $<5$ years, 0.56 (95\% CI 0.34 to 0.92 ) for age $<6$ years and there was only one study in the 5-16 and $<3$ years age groups. In figure 5 , the level of heterogeneity was high for ages $<5$ and $<6$ years after subgroup analysis (figure 5 ). Moreover, 


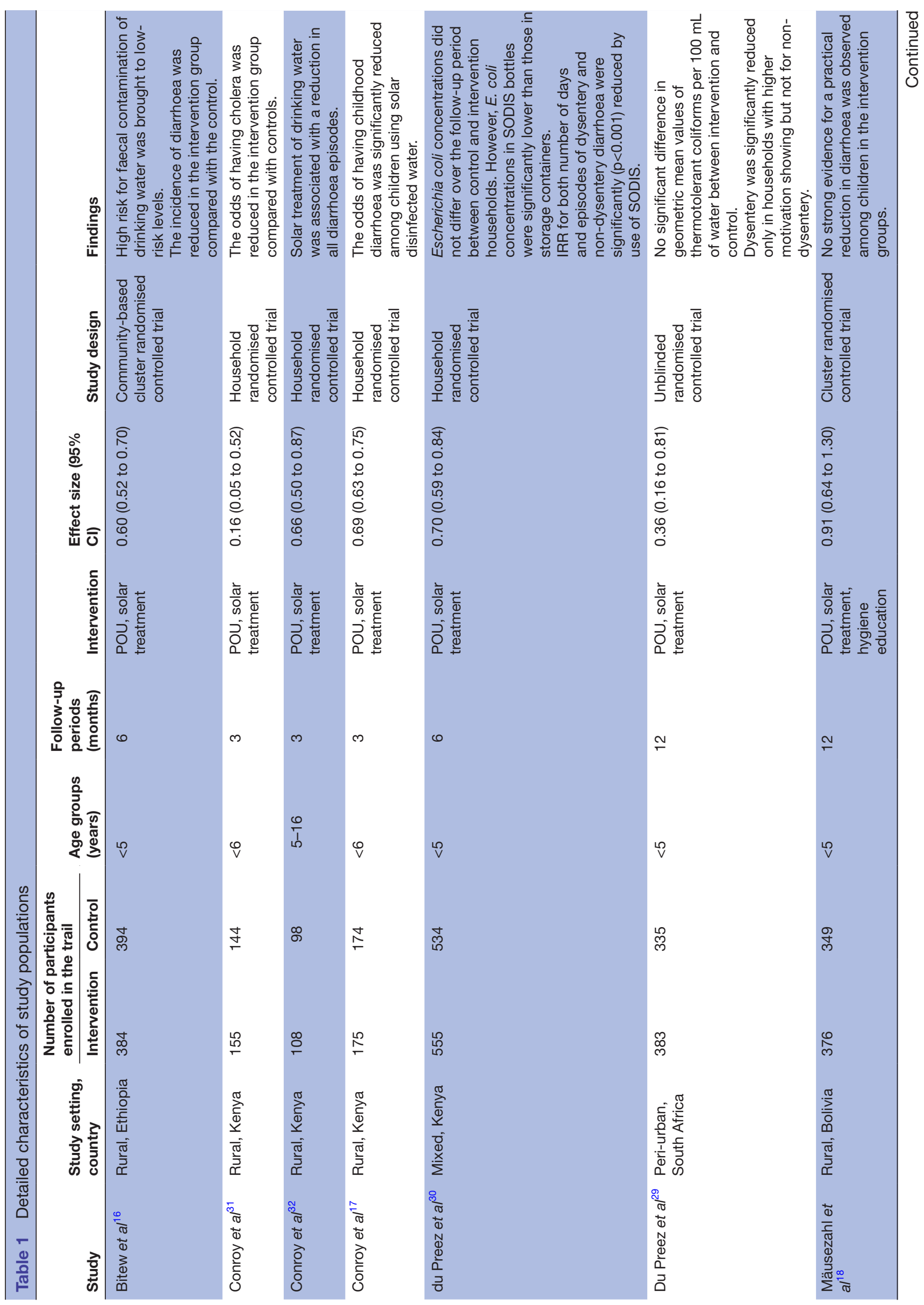




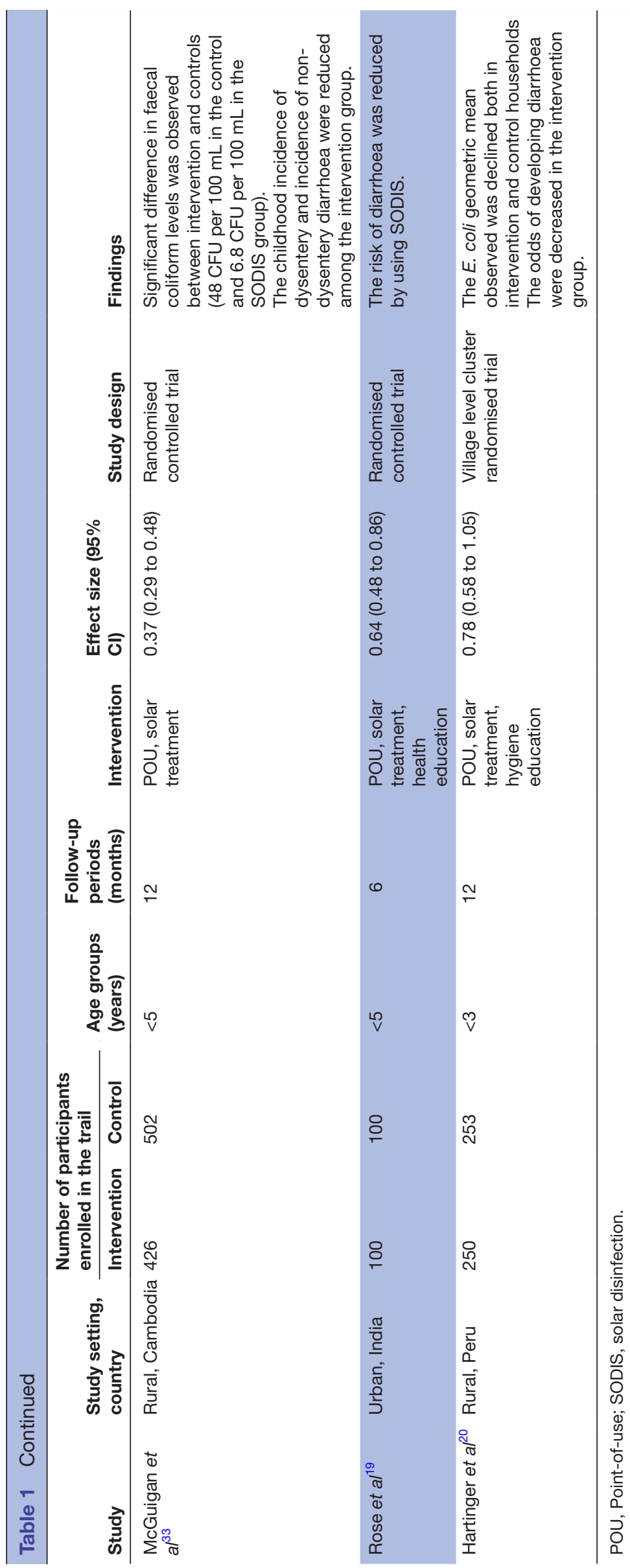

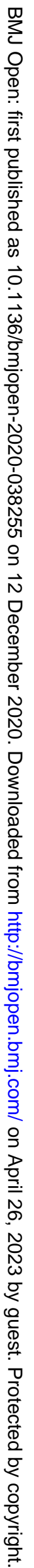


Bitew et al. 2018

Conroy, et al 1996

Conroy, et al. 1999

Conroy,et al. 2001

du Preez et al. 2011

Du Preez et al. 2010

Hartinger et al. 2016

Mäusezahl et al. 2009

McGuigan et al. 2011

Rose et al . 2005

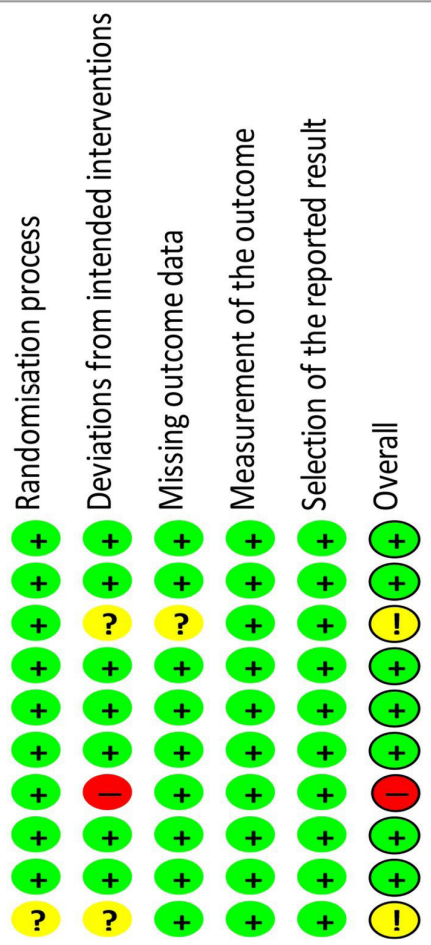

subgroup analysis was computed based on the region of study settings/continent and presented in figure 6 . In the analysis, there is no evidence of heterogeneity for studies from Latin America. The pooled RR of diarrhoea reduction after implementation of the SODIS water treatment method was $37 \%$ for studies from Africa $(\mathrm{RR}=0.63 ; 95 \%$ CI 0.54 to 0.74$), 16 \%$ for studies from Latin America ( $\mathrm{RR}=0.84 ; 95 \%$ CI 0.62 to 1.13 ) and $52 \%$ for studies from Asia ( $R R=0.48 ; 95 \%$ CI 0.36 to 0.63 ) (figure 6 ).

\section{Sensitivity analysis}

To identify a single study influence on the overall analysis, a sensitivity analysis was computed using a random-effects model and the results showed that there is evidence for the effect of a single study on the overall meta-analysis. In table 2, the absence of a study done by McGuigan et $a l^{33}$ slightly increased the overall RR to estimate the effectiveness of SODIS on the reduction of childhood diarrhoea. After removing the study by McGuigan et al, the

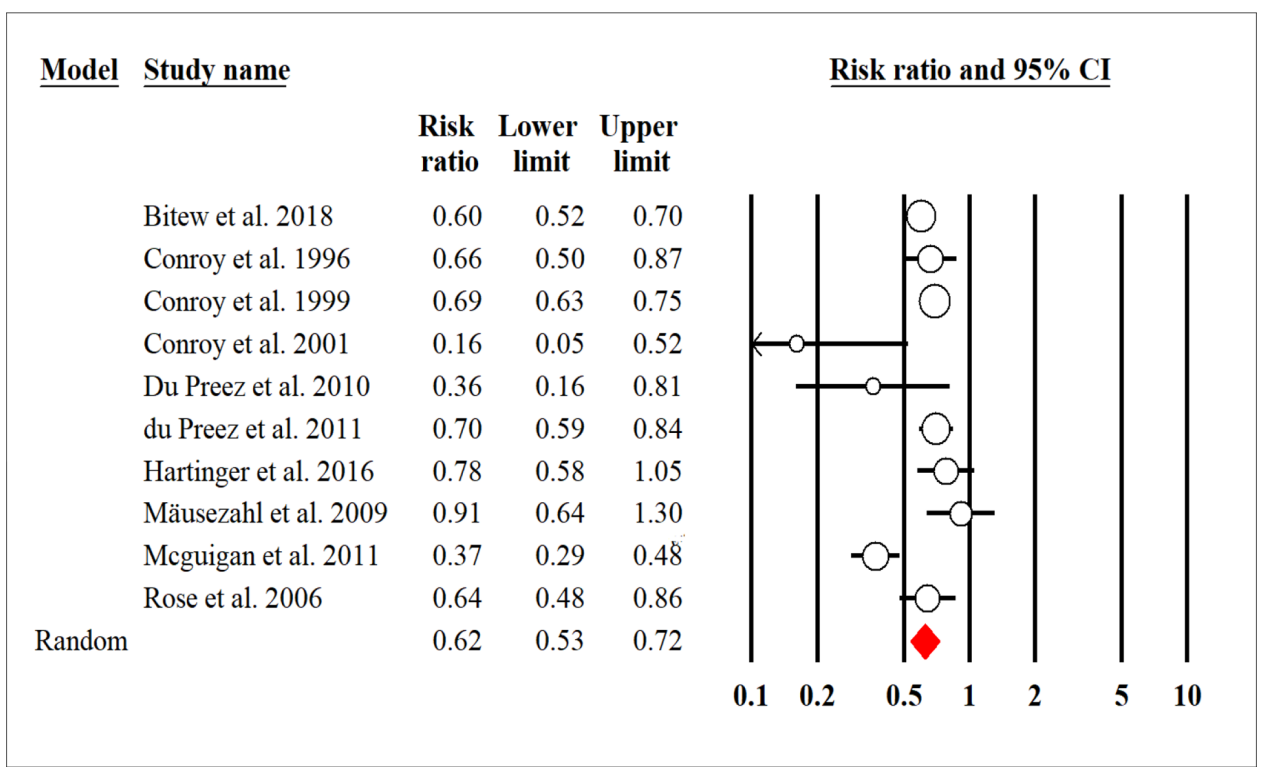

Figure 3 Forest plot showing pooled risk ratio and corresponding 95\% Cls of solar disinfection water treatment to reduce childhood diarrhoea. 


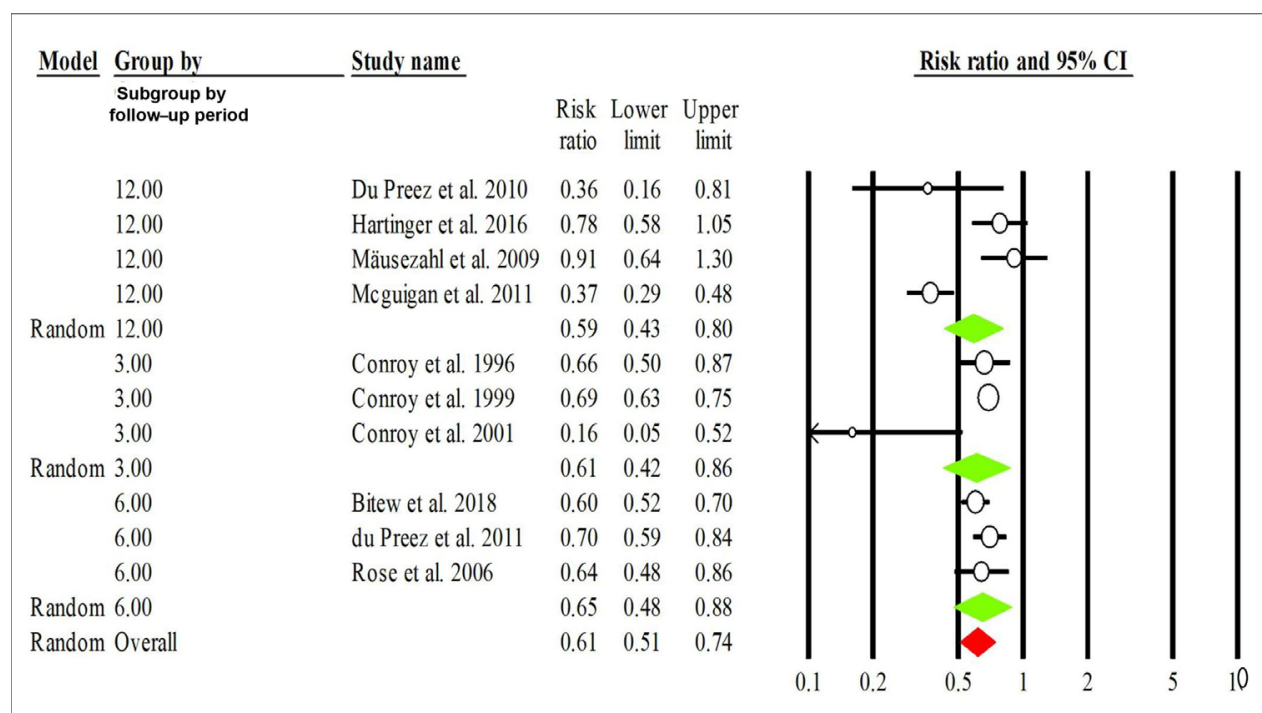

Figure 4 Forest plot showing subgroup analysis: comparing by the length of the follow-up period in months.

overall pooled RR is slightly increased ( 0.67 (95\% CI 0.60 to 0.75$)$ ) and there is no heterogeneity across studies. A statistically significant reduction of diarrhoea occurrence was observed with a risk reduction of $33 \%$ after the study by McGuigan $e t a l^{33}$ was removed (table 2 ).

\section{Publication bias}

Funnel plot and Egger's statistical test at $95 \%$ CI were used to examine the presence of publication bias. The funnel plot was asymmetrical when visually inspected. The likelihood of this funnel plot asymmetry may be related to true heterogeneity or poor methodological quality that led in smaller studies to spuriously inflated effects (figure 7). However, the Egger's test was not statistically significant at a $p$ value of 0.13 . This indicated that there was no statistical evidence of publication bias.

\section{DISCUSSION}

The analysis demonstrates the effectiveness of the SODIS water treatment method for the prevention of diarrhoea. The overall pooled RR indicated a $38 \%$ reduction of diarrhoea through SODIS water treatment methods ( $\mathrm{RR}=0.62 ; 95 \% \mathrm{CI} 0.53$ to 0.72 ). A systematic review of improving water quality intervention for preventing diarrhoea study done by Clasen $e t$ alalso reported that the risk of diarrhoea was reduced by $38 \%$ using SODIS for all ages $(\mathrm{RR}=0.62,95 \%$ CI 0.42 to 0.94$) .{ }^{34} \mathrm{~A}$ systematic review of the impact of drinking water, sanitation and handwashing with soap interventions to reduce childhood diarrhoea, done by Wolf et al report showed a lower reduction of diarrhoeal risk of $12 \%$ ( $\mathrm{RR}=0.88 ; 95 \%$ CI 0.60 to 1.27 ) after adjusting for non-binding using the point-of-use

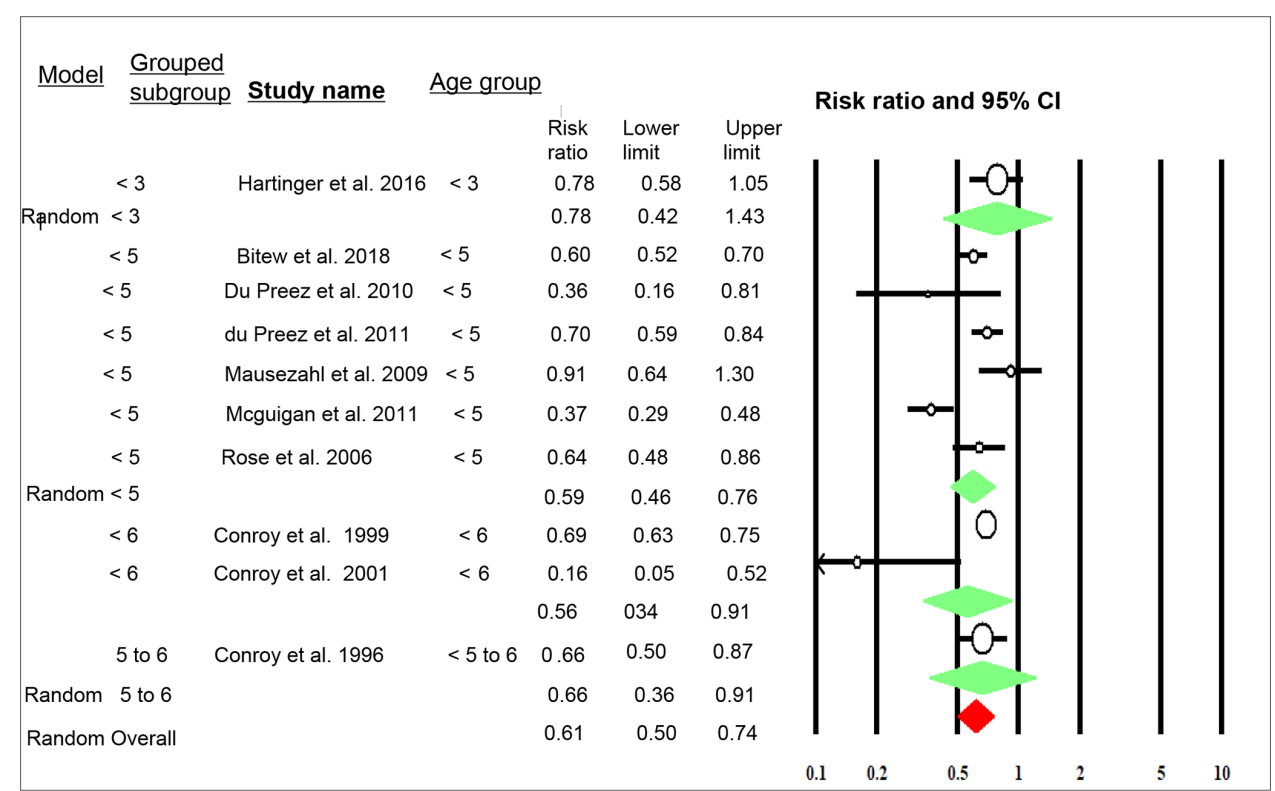

Figure 5 Forest plot showing subgroup analysis: comparing by age of study participants. 


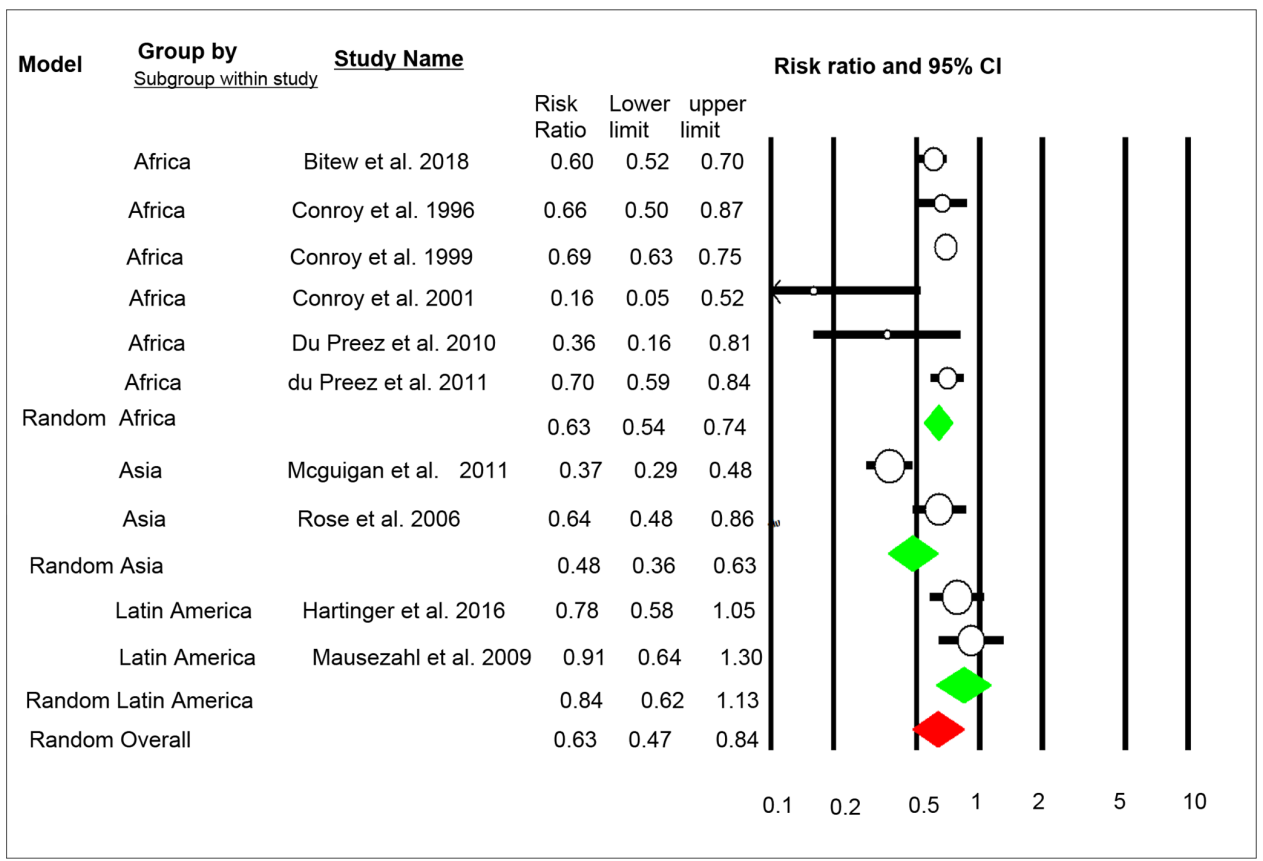

Figure 6 Forest plot showing subgroup analysis: comparing by the region of study settings.

solar treatment for the community depending on the unimproved source. ${ }^{35}$

A systematic review of improving water quality intervention for preventing diarrhoea study done by Clasen $e t$ al also reported that the risk of diarrhoea among children aged $<5$ years of age was reduced by $45 \%$ using point-of-use SODIS. ${ }^{34}$ A review of point-of-use drinking water filtration done by Sobsey et al also reported that SODIS treatment significantly decreased diarrhoeal disease in children in Africa and India, with reductions of $26 \%-37 \% .^{36}$ Similarly, in our study subgroup analysis of children aged $<5$ years of age, the risk of diarrhoea was reduced by $41 \%$ using the SODIS water treatment method. The similarity of the results might be the overlap of the included studies, that is, 6 out of 10 studies included in the pooled estimate calculated by Clasen et al were also included in this analysis. ${ }^{17} 1829303233$

The results of our meta-analysis are nearly consistent with a systematic review of water, sanitation and hygiene interventions to reduce diarrhoea in low-income countries, done by Fewtrell et al, where a pooled effect for household water treatment only improved the risk of diarrhoea by $35 \% .{ }^{6}$ However, this study finding showed a stronger effect of SODIS than the pooled meta-analysis results of the study done to demonstrate the effect of point-of-use chlorine treatment on child diarrhoea, which indicated the effect of diarrhoea was reduced by $29 \%$ after the intervention. ${ }^{37}$ Our study findings also showed a stronger effect of SODIS than other methods of water disinfection reports which showed point-of-use chlorine treatment

\begin{tabular}{llllll}
\hline \multicolumn{5}{l}{ Table 2 Sensitivity analysis of the effectiveness of SODIS water treatment method for the reduction of childhood diarrhoea } \\
\hline $\begin{array}{l}\text { Article removed in the } \\
\text { analysis }\end{array}$ & $\begin{array}{l}\text { Number of studies } \\
\text { included }\end{array}$ & $\begin{array}{l}\text { Random-effects pooled } \\
\text { risk ratio (95\% Cl) }\end{array}$ & Q-value & Q-test p value & I $^{2}$ (\%) \\
\hline Bitew et al (2018) & 9 & $0.62(0.52$ to 0.74$)$ & 33.69 & $<0.0001$ & 76.26 \\
\hline Conroy et al (1996) & 9 & $0.61(0.52$ to 0.73$)$ & 35.10 & $<0.0001$ & 77.21 \\
Conroy et al (1999) & 9 & $0.60(0.49$ to 0.73$)$ & 31.87 & $<0.0001$ & 74.89 \\
Conroy et al (2001) & 9 & $0.63(0.55$ to 0.73$)$ & 29.75 & $<0.0001$ & 73.11 \\
du Preez et al (2011) & 9 & $0.61(0.51$ to 0.72$)$ & 34.39 & $<0.0001$ & 76.74 \\
Du Preez et al (2010) & 9 & $0.63(0.54$ to 0.73$)$ & 33.04 & $<0.0001$ & 75.79 \\
Mäusezahl et al (2009) & 9 & $0.59(0.51$ to 0.70$)$ & 31.59 & $<0.0001$ & 74.67 \\
McGuigan et al (2011) & 9 & $0.67(0.60$ to 0.75$)$ & 14.55 & 0.0690 & 45.01 \\
Rose et al (2006) & 9 & $0.62(0.52$ to 0.73$)$ & 35.09 & $<0.0001$ & 77.21 \\
Hartinger et al (2016) & 9 & $0.60(0.51$ to 0.71$)$ & 33.63 & $<0.0001$ & 76.21
\end{tabular}

SODIS, solar disinfection. 


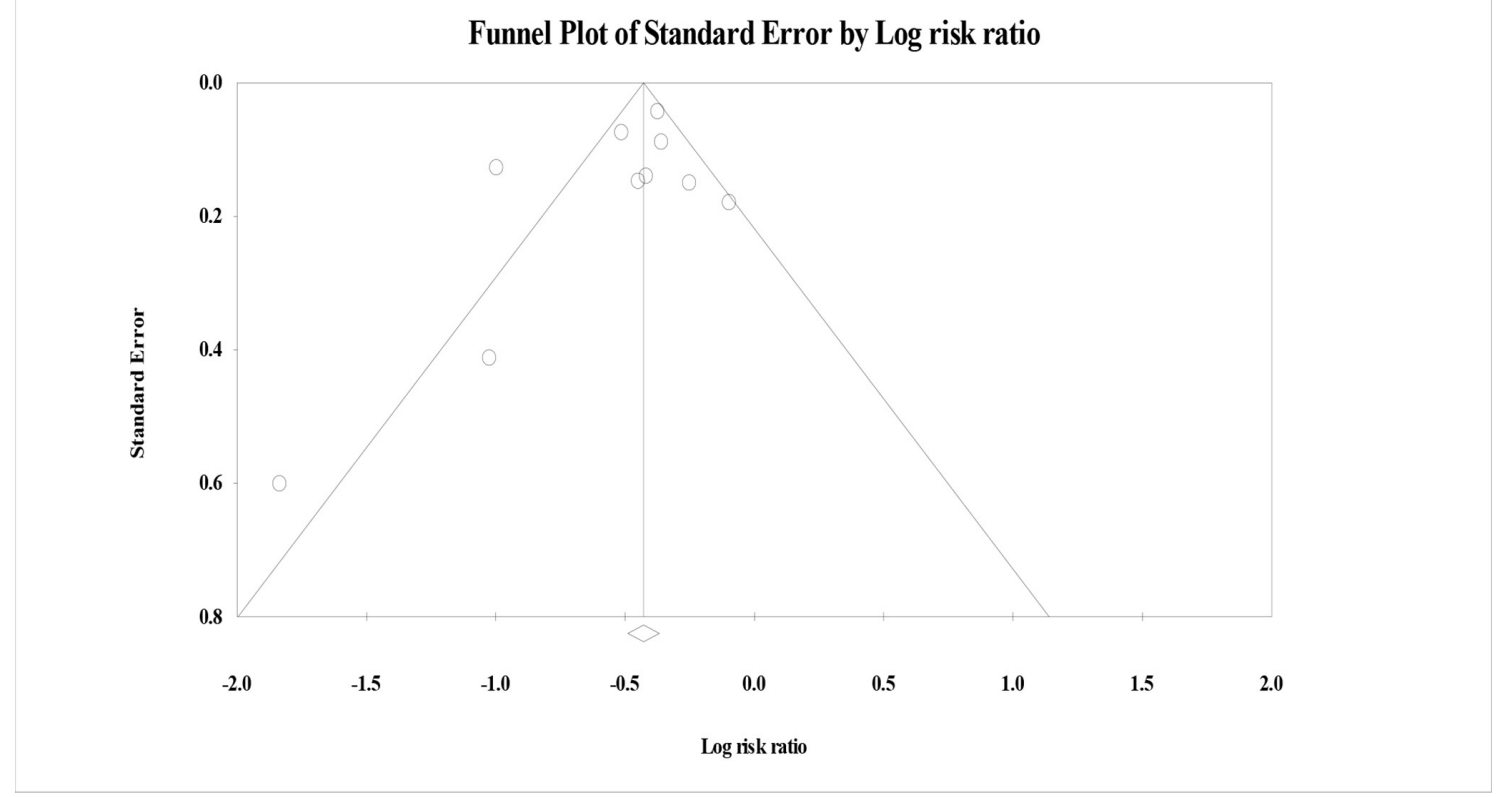

Figure 7 Funnel plot of studies included in the analysis of the effectiveness of solar disinfection on the reduction of childhood diarrhoea.

to have reduced the risk of diarrhoea by $9 \%$ among the community using the unimproved source water supply. ${ }^{35}$ The discrepancy could be due to the difference in the study sample size or the length of the follow-up period of the interventions or study design.

However, compared with a review of point-of-use drinking water filtration done by Sobsey et al where the risk of diarrhoea reduced by $46 \%-63 \%$ using different types of filtration drinking water treatment methods, ${ }^{36}$ our finding was less. A systematic review and meta-analysis done by Cohen and Colford showed boiling the drinking water before consumption also affects childhood diarrhoea. ${ }^{38}$ Our findings are also consistent with these results, although a direct comparison is difficult because they report results ranked by the measure of ORs rather than the RRs.

The evidence from this meta-analysis shows that there is a reduction in improvement in the risk of diarrhoea and the studies included were homogenised at 6 months follow-up compared ${ }^{16} 1930$ with those followed for 3 months and 12 months. ${ }^{1718202931-33}$ The difference could be assumed that the 3 months follow-up of the interventions was not long enough to get any great significant changes comparatively. The use of SODIS for water treatment has a limitation as it requires safe storage after disinfection since the intervention provides no residual disinfectant. ${ }^{38}{ }^{39}$ Similarly, in the 12 months of follow-up, the motivation of participants for safe storage might be lowered over time.

This meta-analysis has some limitations. First, we tried to include only published articles, excluding unpublished articles/resources. The restriction to studies written in the English language was another limitation of this metaanalysis. In addition, the differences in the study settings (urban or rural) or the environments under which the intervention was carried out were also a limitation of this study. The other limitation of this analysis was that we used a limited number of studies.

In conclusion, the results of this systematic review and meta-analysis showed that the intervention of SODIS water treatment had significantly reduced the risk of childhood diarrhoea. There was some bias, but after sensitivity analysis, the effect was still apparent. The exclusion of one study reduced the heterogeneity. Further high-quality studies are needed to definitively determine whether SODIS water treatment is an important method to reduce childhood diarrhoea. Our meta-analysis will need to be updated as the results of future studies become available.

Acknowledgements The authors would like to thank the authors of the studies they used to conduct this study.

Contributors NES developed the research question, methods and wrote the first draft of the manuscript. NES, BMA, SRG, ABH and DOD assisted with the analysis and interpretation of the data and critically reviewed the manuscript. All authors have read and approved the final manuscript.

Funding The authors have not declared a specific grant for this research from any funding agency in the public, commercial or not-for-profit sectors.

Competing interests None declared.

Patient consent for publication Not required.

Provenance and peer review Not commissioned; externally peer reviewed.

Data availability statement Data are available on reasonable request. Not applicable.

Supplemental material This content has been supplied by the author(s). It has not been vetted by BMJ Publishing Group Limited (BMJ) and may not have been peer-reviewed. Any opinions or recommendations discussed are solely those of the author(s) and are not endorsed by BMJ. BMJ disclaims all liability and responsibility arising from any reliance placed on the content. Where the content includes any translated material, BMJ does not warrant the accuracy and reliability of the translations (including but not limited to local regulations, clinical guidelines, 
terminology, drug names and drug dosages), and is not responsible for any error and/or omissions arising from translation and adaptation or otherwise.

Open access This is an open access article distributed in accordance with the Creative Commons Attribution Non Commercial (CC BY-NC 4.0) license, which permits others to distribute, remix, adapt, build upon this work non-commercially, and license their derivative works on different terms, provided the original work is properly cited, appropriate credit is given, any changes made indicated, and the use is non-commercial. See: http://creativecommons.org/licenses/by-nc/4.0/.

\section{ORCID iD}

Negasa Eshete Soboksa http://orcid.org/0000-0003-3451-175X

\section{REFERENCES}

1 UNICEF/ WHO. Diarrhea: why children are still dying and what can be done, 2009.

2 Prüss-Ustün A, Bartram J, Clasen T, et al. Burden of disease from inadequate water, sanitation and hygiene in low- and middle-income settings: a retrospective analysis of data from 145 countries. Trop Med Int Health 2014;19:894-905.

3 WHO. Drinking-Water. Geneva, Switzerland: WHO, 2019. https:// www.who.int/news-room/fact-sheets/detail/drinking-water

4 Semenza JC, Roberts L, Henderson A, et al. Water distribution system and diarrheal disease transmission: a case study in Uzbekistan. Am J Trop Med Hyg 1998;59:941-6.

5 Waddington $\mathrm{H}$, Snilstveit $\mathrm{B}$, White $\mathrm{H}$, et al. Water, sanitation, and hygiene interventions to combat childhood diarrhoea in developing countries. International Initiative for Impact Evaluation 2009;2014 https://www.researchgate.net/publication/228378510

6 Fewtrell L, Kaufmann RB, Kay D, et al. Water, sanitation, and hygiene interventions to reduce diarrhoea in less developed countries: a systematic review and meta-analysis. Lancet Infect Dis 2005;5:42-52.

7 Clasen T, Schmidt W-P, Rabie T, et al. Interventions to improve water quality for preventing diarrhoea: systematic review and metaanalysis. BMJ 2007;334:782-10.

8 Schmidt W-P, Cairncross S. Household water treatment in poor populations: is there enough evidence for scaling up now? Environ Sci Technol 2009;43:986-92.

9 Clasen TF, Cairncross S. Household water management: Refining the dominant paradigm. Trop Med Int Health 2004;9:187-91.

10 Luzi S, Tobler M, Suter F. Sandec: Sanitation, Water, and Solid Waste for Development SODIS manual, 2016. Available: www.sodis.ch

11 World Health Organization. Water treatment at the household level and on a large scale, 2016. World Health Organization. Available: https://www.who.int/water_sanitation_health/emergencies/qa/ emergencies_qa16/en/ [Accessed June 1, 2019].

12 McGuigan KG, Joyce TM, Conroy RM, et al. Solar disinfection of drinking water contained in transparent plastic bottles: characterizing the bacterial inactivation process. J Appl Microbiol 1998;84:1138-48. doi:10.1046/j.1365-2672.1998.00455.x

13 Wegelin M, Canonica S, Mechsner K, et al. Solar water disinfection : scope of the process and analysis of radiation experiments. Journal of Water Supply Research and Technology 1994:43-169 http://www. irc.nl/docsearch/title/107952

14 McGuigan KG, Conroy RM, Mosler H-J, et al. Solar water disinfection (SODIS): a review from bench-top to roof-top. J Hazard Mater 2012;235-236:29-46.

15 Dawney B, Cheng C, Winkler R, et al. Evaluating the geographic viability of the solar water disinfection (SODIS) method by decreasing turbidity with $\mathrm{NaCl}$ : a case study of South Sudan. Appl Clay Sci 2014;99:194-200.

16 Bitew BD, Gete YK, Biks GA, et al. The effect of SODIS water treatment intervention at the household level in reducing diarrheal incidence among children under 5 years of age: a cluster randomized controlled trial in Dabat district, Northwest Ethiopia. Trials 2018;19:1-15.

17 Conroy RM, Meegan ME, Joyce T, et al. Solar disinfection of water reduces diarrhoeal disease: an update. Arch Dis Child 1999;81:337-8.

18 Mäusezahl D, Christen A, Pacheco GD, et al. Solar drinking water disinfection (SODIS) to reduce childhood diarrhoea in rural Bolivia: a cluster-randomized, controlled trial. PLoS Med 2009;6:e1000125-13.
19 Rose A, Roy S, Abraham V, et al. Solar disinfection of water for diarrhoeal prevention in southern India. Arch Dis Child 2006;91:139-41.

20 Hartinger SM, Lanata CF, Hattendorf J, et al. Improving household air, drinking water and hygiene in rural Peru: a communityrandomized-controlled trial of an integrated environmental homebased intervention package to improve child health. Int J Epidemiol 2016;45:dyw242-99.

21 Beller EM, Glasziou PP, Altman DG, et al. PRISMA for Abstracts: reporting systematic reviews in Journal and conference Abstracts. PLoS Med 2013;10:e1001419.

22 Soboksa NE, Gari SR, Hailu AB, et al. The effectiveness of solar disinfection water treatment method for reducing childhood diarrhea: a systematic review and meta-analysis protocol. Syst Rev 2020:9:1-5

23 Moher D, Liberati A, Tetzlaff J, et al. Preferred reporting items for systematic reviews and meta-analyses: the PRISMA statement. PLoS Med 2009;7:889-96.

24 Sterne JAC, Savović J, Page MJ, et al. Rob 2: a revised Cochrane risk-of-bias tool for randomized trials. BMJ. In Press 2019 https:// methods.cochrane.org/

25 Higgins JPT, Thompson SG. Quantifying heterogeneity in a metaanalysis. Stat Med 2002;21:1539-58.

26 Ariff S, Khan U, Turab A, et al. Evaluation of solar disinfection of water intervention delivered through lady health workers in the reduction of diarrheal episodes in under-five children. International Journal of Pediatrics \& Child Care 2016;1:1-10.

27 Gruber JS, Reygadas F, Arnold BF, et al. A stepped wedge, clusterrandomized trial of a household UV-disinfection and safe storage drinking water intervention in rural Baja California sur, Mexico. Am J Trop Med Hyg 2013;89:238-45.

28 Rai B, Pal R, Kar S, et al. Solar disinfection improves drinking water quality to prevent diarrhea in under-five children in sikkim, India. J Glob Infect Dis 2010;2:221.

29 Du Preez M, Mcguigan KG, Conroy RM. Solar disinfection of drinking water in the prevention of dysentery in South African children aged under 5 years: the role of participant motivation. Environ Sci Technol 2010;44:8744-9.

30 du Preez M, Conroy RM, Ligondo S, et al. Randomized intervention study of solar disinfection of drinking water in the prevention of dysentery in Kenyan children aged under 5 years. Environ Sci Technol 2011;45:9315-23.

31 Conroy RM, Meegan ME, Joyce T, et al. Solar disinfection of drinking water protects against cholera in children under 6 years of age. Arch Dis Child 2001;85:293-5.

32 Conroy RM, Elmore-Meegan M, Joyce T, et al. Solar disinfection of drinking water and diarrhoea in Maasai children: a controlled field trial. Lancet 1996;348:1695-7.

33 McGuigan KG, Samaiyar P, du Preez M, et al. High compliance randomized controlled field trial of solar disinfection of drinking water and its impact on childhood diarrhea in rural Cambodia. Environ Sci Technol 2011;45:7862-7.

34 Clasen TF, Alexander KT, Sinclair D, et al. Interventions to improve water quality for preventing diarrhea. Cochrane Database of Systematic Reviews Interventions 2015;10:1-178.

35 Wolf J, Hunter PR, Freeman MC, et al. Impact of drinking water, sanitation and handwashing with soap on childhood diarrhoeal disease: updated meta-analysis and meta-regression. Trop Med Int Health 2018;23:508-25.

36 Sobsey MD, Stauber CE, Casanova LM, et al. Point of use household drinking water filtration: a practical, effective solution for providing sustained access to safe drinking water in the developing world. Environ Sci Technol 2008;42:4261-7.

37 Arnold BF, Colford JM. Treating water with chlorine at point-of-use to improve water quality and reduce child diarrhea in developing countries: a systematic review and meta-analysis. Am J Trop Med Hyg 2007;76:354-64.

38 Cohen A, Colford JM. Effects of boiling drinking water on diarrhea and pathogen-specific infections in low- and middle-income countries: a systematic review and meta-analysis. Am J Trop Med Hyg 2017;97:1362-77.

39 Wright J, Gundry S, Conroy R. Household drinking water in developing countries: a systematic review of microbiological contamination between source and point-of-use. Trop Med Int Health 2004;9:106-17. 